\title{
Flushing, CTCAE 5.0
}

National Cancer Institute

\section{Source}

National Cancer Institute. Flushing, CT CAE 5.0. NCI Thesaurus. Code C146643.

A disorder characterized by episodic reddening of the skin, especially face, neck, or chest. 